\title{
Hyperventilation in panic disorder patients and healthy first-degree relatives
}

A.E. Nardi ${ }^{1}$, A.M. Valença ${ }^{1}$, I. N ascimento ${ }^{1}$, M.A. Mezzasalma ${ }^{1}$,

F.L. Lopes ${ }^{1}$ and W.A. Zin ${ }^{2}$

\author{
${ }^{1}$ Laboratório de Pânico e Respiração, Instituto de Psiquiatria, and \\ 2Laboratório de Fisiologia da Respiração, Instituto de Biofísica Carlos Chagas Filho, \\ Universidade Federal do Rio de Janeiro, Rio de Janeiro, RJ, Brasil
}

\section{Correspondence}

\section{A.E. Nardi}

Laboratório de Fisiologia da Respiração, IPUB-UFRI

22410-003 Rio de Janeiro, RJ Brasil

Fax: + 55-21-523-6839

E-mail: aenardi@ novanet.com.br

Research supported by CN Pq (No. 300500/93-9).

Received December 1, 1999 Accepted August 7, 2000

\section{Abstract}

Our aim was to observe the induction of panic attacks by a hyperventilation challenge test in panic disorder patients (DSM-IV) and their healthy first-degree relatives. We randomly selected 25 panic disorder patients, 31 healthy first-degree relatives of probands with panic disorder and 26 normal volunteers with no family history of panic disorder. All patients had no psychotropic drugs for at least one week.

\section{Key words} - Panic attacks

- Respiration

- Anxiety disorder

- Ventilation They were induced to hyperventilate ( 30 breaths/min) for $4 \mathrm{~min}$ and anxiety scales were applied before and after the test. A total of $44.0 \%$ $(\mathrm{N}=11)$ panic disorder patients, $16.1 \%(\mathrm{~N}=5)$ of first-degree relatives and $11.5 \%(\mathrm{~N}=3)$ of control subjects had a panic attack after hyperventilating $\left(\chi^{2}=8.93\right.$, d.f. $\left.=2, \mathrm{P}=0.011\right)$. In this challenge test the panic disorder patients were more sensitive to hyperventilation than first-degree relatives and normal volunteers. Although the hyperventilation test has a low sensitivity, our data suggest that there is no association between a family history of panic disorder and hyperreactivity to an acute hyperventilation challenge test. Perhaps cognitive variables should be considered to play a specific role in this association since symptoms of a panic attack and acute hyperventilation overlap.

\section{Introduction}

Hyperventilation is an increase in the amount of inhaled and exhaled air per minute, exceeding the amount necessary for normal cell metabolism (1). In this condition, ventilation exceeds cellular metabolism, resulting in an elimination of $\mathrm{CO}_{2}$ greater than its production, which causes a decline in the arterial partial pressure of carbon dioxide $\left(\mathrm{PCO}_{2}\right)(1,2)$.

Hyperventilating at 30 breaths per minute, although causing a significant drop in end- tidal $\mathrm{CO}_{2}$ to conventionally accepted levels of hypocapnia, seems to be a less convincing panicogenic challenge than $\mathrm{CO}_{2}$ inhalation $(3,4)$. However, for a small group of panic disorder patients hyperventilation may be a safe and easy test for a more precise diagnosis. Anyway, hyperventilation has been considered as a cause, a correlate and a consequence of panic attacks (5). Stress-induced hyperventilation produces symptoms that people tend to misinterpret as life threatening if they are unaware of the consequences of overbreathing $(1,5)$. Misinterpretation of 
these symptoms increases fear and activates the autonomic nervous system, resulting in increasing respiratory frequency that will further dissipate carbon dioxide and intensify hypocapnic symptoms $(1,5,6)$.

Respiratory abnormalities are associated with anxiety, particularly with panic attacks $(1,2)$. Symptoms such as shortness of breath, "empty-head" feeling, dizziness, paresthesias and tachypnea have been described in the psychiatric and respiratory physiology related to panic disorder $(2,3)$.

A high prevalence of anxiety disorders has been found among first-degree relatives of subjects with panic attacks. Balon et al. (7) infused sodium lactate in 45 control subjects. An investigator, blind to the outcome of the infusion study, obtained family histories of 160 relatives. There was no significant difference in the prevalence of mood disorders and substance abuse between firstdegree relatives of subjects with $(\mathrm{N}=45)$ and without $(\mathrm{N}=115)$ panic attacks, but there was a difference in the prevalence of anxiety disorders, suggesting that individuals with a family history of anxiety disorders may be vulnerable to lactate-induced panic attacks.

Perna et al. (8) tested the hypothesis that hyperreactivity to $\mathrm{CO}_{2}$ in healthy subjects represents an underlying familial vulnerability to panic disorder. They studied 84 panic disorder patients, 23 healthy first-degree relatives of probands with panic disorder, and 44 healthy subjects with no family history of panic disorder. The first-degree relatives of the probands with panic disorder reacted significantly more than the healthy subjects without a family history of panic disorder. These findings suggested an association between a family history of panic disorder and hyperreactivity to $35 \% \mathrm{CO}_{2}$ inhalation.

Multiple lines of evidence have shown biological, and especially respiratory, symptoms involved in anxiety disorders $(3,4,9)$. The respiratory challenge test strategies have been especially fruitful in generating hy- potheses about panic disorder $(10,11)$.

Since there is substantial evidence that panic disorder runs in families (12), and that affected subjects may share some biological sensitivity $(7,8)$, the objective of the present study was to determine if there is any difference in induced panic attacks using room air hyperventilation ( 30 breaths/min) over a period of 4 min among panic disorder patients, some of their healthy first-degree relatives and a control group.

\section{Patients and Methods}

We randomly selected 25 panic disorder patients, 14 women and 11 men (mean age \pm SD: $33.8 \pm 9.4$ years), and 31 of their healthy first-degree relatives (parents or children), 19 women and 12 men (mean age \pm SD: 41.5 \pm 12.8 years), in the Laboratory of Panic and Respiration of the Institute of Psychiatry, Federal University of Rio de Janeiro. A group of 26 subjects with no family history of panic disorder (14 women and 12 men, mean age \pm SD: $29.7 \pm 7.9$ years) was used for comparison. The diagnosis was made by one rater (I.N.) using the Structured Clinical Interview Diagnostic (SCID) (13) for DSM-IV (14). Patients who met DSM-IV criteria for current major depression, bipolar disorder, obsessive-compulsive disorder, schizophrenia, delusional or psychotic disorders, organic brain syndrome, severe personality disorder, epilepsy, or substance abuse or dependence (during the previous year) were excluded. Patients with comorbid dysthymia, generalized anxiety disorder or past major depression were included if panic disorder was judged to be the principal diagnosis. The protocol was explained to the subjects, who signed a voluntary written consent to participate in the study. The subjects were informed that they would be asked to hyperventilate room air and that the procedure was not dangerous but that anxiety or panic could occur during the session. Our local Ethics Committee approved the proto- 
col, which complied with the principles of the Declaration of Helsinki. Inclusion criteria were: 18 to 55 years of age, occurrence of at least three panic attacks in the two weeks before the challenge test day in panic disorder patients, no use of any psychotropic drugs for at least one week by any subject, and a negative urine test for benzodiazepines and other medications. Exclusion criteria were: unstable medical condition, psychotherapy during the study, use of any regular antipsychotic, antidepressant, regular benzodiazepine or nonbenzodiazepine anxiolytic medication for 4 weeks, or fluoxetine for 5 weeks before the test, or the presence of suicidal risk. Subjects with a history of respiratory disease and smokers were also excluded.

The first-degree relatives (parents or children) and the comparison group were also assessed by the SCID (13). They were free of any history of current panic disorder, major mood disorder, schizophrenia, and current substance abuse disorders.

All subjects underwent a physical examination and laboratory exams to ensure they were healthy enough to participate in a hyperventilation challenge test. They had no respiratory or cardiovascular abnormalities and were free of caffeine ingestion for one day. The test was conducted in the usual examination room, with no changes made in the environment. All subjects were asked to relax for $10 \mathrm{~min}$. We then checked respiratory frequency, pulse and blood pressure and repeated the measurements 1 and 5 min after the test. To measure the baseline anxiety level, before hyperventilating subjects were asked to complete the Subjective Units of Disturbance Scale (SUDS), a semiquantitative evaluation method ranging from $0=$ no anxiety, to $10=$ maximum anxiety (15), and the Diagnostic Symptom Questionnaire (DSQ) (15) adapted for DSM-IV in which the presence and level of discomfort of panic symptoms experienced after the inhalations were rated on a $0-4$ point scale $(0=$ none, 4
$=$ very severe). Both self-rating scales, the SUDS and the DSQ, had been tested by back translation but not by test-retest examination. After the test the SUDS and DSQ were completed again. The subjects completed them independent of the raters. On the basis of the DSQ, a panic attack was defined as the following: 1) four or more symptoms of a panic attack from the DSM-IV; 2) at least one of the cognitive symptoms of a panic attack from the DSM-IV (e.g., fear of dying or of losing sanity or control); 3) feeling of panic or fear, similar to spontaneous panic attacks recorded on a card which the raters were not permitted to observe, and 4) agreement at clinical diagnosis evaluation between two diagnosis-blinded raters from the team during the test. The feeling of a panic attack reported by the subjects was also examined in order to compare agreement between raters and subjects about panic attacks.

We explained to the subjects what they were expected to do and submitted them to a 30 -s period of training for hyperventilation. The subject then relaxed for an additional 10 min, after which we induced hyperventilation (30 respiratory movements per minute over a period of $4 \mathrm{~min}$ ) with a rater counting aloud the movements measured with a chronometer. Immediately after this period we evaluated the level of anxiety and the induction of a panic attack.

\section{Statistical analysis}

Panic rates for the three groups, also separated according to rater and subject ratings and by gender, were compared by the chi-square test. Data concerning the effects of hyperventilation and time of observation were tested by ANOVA. Pairwise comparisons of the treatment groups were performed at end-point, using Fisher's protected least significant difference method. The KruskalWallis test was also applied to the main efficacy parameters. The level of significance was set at $5 \%$. 


\section{Results}

Table 1 shows the panic rates assigned by the raters and by the subjects during the challenge test. Significantly more panic patients had a panic attack in response to hyperventilation than first-degree relatives or the control group according to both rater groups: $44.0 \%(\mathrm{~N}=11)$ panic disorder patients, $16.1 \%(\mathrm{~N}=5)$ first-degree relatives and $11.5 \%(\mathrm{~N}=3)$ control subjects had a panic attack after hyperventilating. There was no significant sex difference in any group (ANOVA, $\mathrm{F}=1.42$, d.f. $=2, \mathrm{P}=0.957$ ).

Table 2 shows the SUDS subjective anxiety level measurement before and after hy-

Table 1 - Response of patients with panic disorder, healthy first-degree relatives and normal control subjects challenged with room air hyperventilation.

Raters evaluation of panic attacks: $\chi^{2}=8.93$, d.f. $=2, \mathrm{P}=0.011$ (panic disorder vs relatives; $\chi^{2}$ with Yates correction $=3.99, \mathrm{P}=0.045$ ) (panic disorder vs control; $\chi^{2}$ with Yates correction $=5.21, P=0.022$ ) (relatives vs control; Fisher exact test, two-tailed, $\mathrm{P}=0.715)$. Subject evaluation of panic attacks: $\chi^{2}=14.88$, d.f. $=2, P=0.0005$ (panic disorder vs relatives; $\chi^{2}$ with Yates correction $=8.24, \mathrm{P}=0.004$ ) (panic disorder vs control; $\chi^{2}$ with Yates correction $=7.90, P=0.004$ ) (relatives vs control; Fisher exact test, two-tailed, $\mathrm{P}=1.00$ ).

\begin{tabular}{lccr}
$\begin{array}{l}\text { Rating after } \\
\text { hyperventilation }\end{array}$ & $\begin{array}{c}\text { Panic disorder } \\
(\mathrm{N}=25)\end{array}$ & $\begin{array}{r}\text { First-degree relative } \\
(\mathrm{N}=31)\end{array}$ & $\begin{array}{r}\text { Normal control } \\
(\mathrm{N}=26)\end{array}$ \\
\hline $\begin{array}{l}\text { Raters } \\
\text { Panic }\end{array}$ & $11(44.0 \%)$ & $5(16.1 \%)$ & $3(11.5 \%)$ \\
No panic & $14(56.0 \%)$ & $26(83.9 \%)$ & $23(88.5 \%)$ \\
Subject & & & \\
Panic & $13(52.0 \%)$ & $4(12.9 \%)$ & $3(11.5 \%)$ \\
No panic & $2(48.0 \%)$ & $27(87.1 \%)$ & $23(88.5 \%)$
\end{tabular}

Table 2 - Subjective anxiety levels rated by the subjects just before and after hyperventilation (mean $\pm \mathrm{SD}$ ).

SUDS, Subjective Units of Disturbance Scale. ANOVA, $F=2.311$, d.f. $=2$, $\mathrm{P}=0.106$ (Fisher's protected least significant difference: panic disorder vs relatives, $\mathrm{P}=0.058$; panic disorder vs control, $\mathrm{P}=0.070$; relatives vs control, $\mathrm{P}=0.997)$.

\begin{tabular}{lccc}
\hline Self-rating & $\begin{array}{c}\text { Panic disorder } \\
(\mathrm{N}=25)\end{array}$ & $\begin{array}{c}\text { First-degree relative } \\
(\mathrm{N}=31)\end{array}$ & $\begin{array}{c}\text { Normal control } \\
(\mathrm{N}=26)\end{array}$ \\
\hline SUDS before & $3.8 \pm 3.1$ & $2.7 \pm 3.8$ & $2.4 \pm 1.9$ \\
SUDS after & $8.5 \pm 4.6$ & $4.1 \pm 4.0$ & $3.5 \pm 3.2$
\end{tabular}

perventilating. Patients with panic disorder tended to be more sensitive to the effects of hyperventilation than first-degree relatives and normal controls. All subjects showed an increase in anxiety levels after hyperventilating. The Kruskal-Wallis test $(2.574$, d.f. $=$ $2, \mathrm{P}=0.276$ ) was also applied to the main efficacy parameters.

\section{Discussion}

This study compares panic disorder patients and some of their first-degree relatives in a hyperventilation challenge test with a control group. In our sample the hyperventilation challenge test (30 breaths/min over a period of $4 \mathrm{~min}$ ) differentiated panic disorder patients from normal controls. We found no difference in sex or anxiety response among our groups. Perhaps these hyperventilation-sensitive panic disorder patients will be clearly identified in the future with a more sophisticated methodology. Some methodological improvements can be made in order to increase the sensitivity of the test.

During voluntary hyperventilation, patients with panic disorder often recognize some of the symptoms felt during a panic attack (16-18). For this reason hypocapnia may be an important factor in the anxiety that occurs during a panic attack and hyperventilation $(4,11)$. These data suggest that hyperventilation occurs during some panic attacks. Papp et al. (11), using basal arterial blood gas levels, found that only the patients who had panic attacks after lactate infusion were chronic hyperventilators, as indicated by low levels of blood bicarbonate when compared to controls. This study also shows that hyperventilation is a relatively mild panicogenic agent.

In a preliminary study (19) we observed the induction of panic attacks by hyperventilation in a group of panic disorder patients (DSM-IV). Thirteen panic disorder patients and 11 normal volunteers were randomly selected and induced to hyperventilate (30 
breaths/min) for $3 \mathrm{~min}$. Anxiety scales were applied before and after the test. Nine (69.2\%) panic disorder patients and one $(9.1 \%)$ of the control subjects had a panic attack after hyperventilating. The difference observed in these two studies may be due to a better training of the research group in the hyperventilating challenge test, the size of the samples or the severity of the disorder.

Several other studies do not give support to the theory that hyperventilation arouses panic attacks or contributes to their severity $(11,20,21)$. As hyperventilation frequently occurs, it may not be a cause or an important component of panic attacks. It may be that hyperventilation is a consequence of panic attacks in hyperventilation-predisposed individuals $(10,21,22)$. A variety of studies have shown that differences between individuals with and without panic disorder in measurements of panic during hyperventilation challenges are considerably lower than those observed in $\mathrm{CO}_{2}$ challenges $(23,24)$. In addition, panic disorder individuals appeared to be less compliant with the hyperventilation instructions than were other groups (23).

Gorman et al. (17) conducted a study on 12 patients with panic disorder or agoraphobia with panic attacks (DSM-III). The patients were asked to hyperventilate (30 respiratory movements $/ \mathrm{min}$ ) for $15 \mathrm{~min}$. After the test the patients filled in the Acute Panic Inventory, which measures the severity of the typical panic symptoms. Three $(25 \%)$ of the 12 patients had panic attacks after this procedure, demonstrating that the induction of respiratory alkalosis would not be enough to provoke panic attacks in all patients. Acute hyperventilation is a probable cause of panic attacks in a percentage of patients with panic disorder $(1,4,21)$.

Zandbergen et al. (21) looked for evidence of chronic hyperventilation in 18 patients with panic disorder (DSM-III-R) by measuring their arterial $\mathrm{PCO}_{2}$, base excess, bicarbonate and $\mathrm{pH}$. Comparing the data with those obtained for 18 healthy controls and 12 patients with other anxiety disorders (obsessive-compulsive disorder and generalized anxiety disorder) the authors found no significant differences in base excess or bicarbonate levels between patients with panic disorder, other anxiety disorders and healthy controls. This result also suggests that there is no chronic hyperventilation in patients with panic disorder.

Panic disorder patients exhibit both behaviorally and physiologically abnormal responses to respiratory challenge tests $(10,11)$. Panic patients reported significantly more panic attacks and anxiety during the challenges than normal volunteers $(1,2,9)$. In an anxiety disorder sample (9), patients with DSM-III agoraphobia, panic disorder, generalized anxiety disorder, social phobia and normal controls underwent a series of experimental procedures and measurements to determine whether panic attack patients show a greater tendency towards hyperventilation that is independent from their anxiety levels. The agoraphobia and panic disorder patients did not show significantly lower levels of expired $\mathrm{PCO}_{2}$ at rest than the other anxious or non-anxious groups. However, the panic attack patients did show significantly higher levels of anxiety and hyperventilatory symptoms during a hyperventilation test or during breathing 5\% $\mathrm{CO}_{2}$ in air. A strong relationship was found between hyperventilatory symptoms and anxiety in all anxiety disorder groups of patients and in the controls. On the basis of these results, Holt and Andrews (9) concluded that agoraphobia and panic disorder patients do not show a unique tendency toward hyperventilation, but rather that their hyperventilatory symptoms and perhaps intermittent overbreathing episodes are a function of the high levels of anxiety they experience. Their method probably did not distinguish panic disorder patients from social phobics because they relied only on the patients' subjective judgement for the diagnosis of a panic attack, the hyperventilation lasted just $1.5 \mathrm{~min}$ and $36 \%$ of the panic 
disorder patients and $31 \%$ of the social phobic patients were on medication during the test. In our hyperventilatory challenge test the results were statistical significant for panic attacks (Table 1) and the anxiety levels (Table 2) tended to show that panic disorder patients may be more sensitive to respiratory tests than first-degree relatives and volunteers. In our study the panic attack diagnostic criteria were clearly defined, patients had not been taking any drug for at least one week and they were induced to hyperventilate for $4 \mathrm{~min}$. Another consideration is that our sample consisted of moderate and severe panic disorder patients.

The present study has some limitations. First, the proband group tested, possibly because of the exclusion criteria, might not be representative of other series of patients with panic disorder. Second, only the healthy relatives who accepted to participate in the test were studied. Some more anxious and perhaps more vulnerable subjects may not have been included.

According to the cognitive approach (25), the catastrophic interpretation of bodily sensations induced by hyperventilation may play a more important role in the panic attack. The erroneous interpretation of bodily sensations as dangerous and threatening would result in an increase in anxiety, which in turn would lead to new sensations, and thus result in a vicious cycle until the panic attack. The respiratory re-training techniques may reduce the severity of symptoms during the panic attack by decreasing the hyperventilatory response $(8,25)$. We also observed that some symptoms of this syndrome (anxiety, faster or deeper breathing, palpitations, tachycardia, dizziness, tremors, feelings of panic, uneasiness, fatigue, crying spells, paresthesias) are similar to the clinical findings of panic disorder, and many of them are part of the diagnostic criteria for panic attacks on the basis of the DSM classification.

Evidence implicating respiratory abnormalities in the pathogenesis of panic attacks is rapidly accumulating. Panic disorder patients seem to be more sensitive to hyperventilation than normal volunteers. Our data support Klein's theory (26) proposing the existence of a "suffocation false alarm" mechanism. According to this theory, one of the mechanisms that signal suffocation is a rise in $\mathrm{CO}_{2}$ concentration. The suffocation false alarm as well as the $\mathrm{CO}_{2}$ hypersensitivity may act in conjunction with cognitive factors to induce panic attacks in panic disorder patients. There still are a number of critical areas in need of exploration before such assertion can be fully validated. These areas include the need to establish in which group of panic disorder patients hyperventilation can be used as a specific test, whether it varies with patient age or sex and to what extent it is cognitively mediated (27). Our results are different from those of Balon et al. (7) and of Perna et al. (8), who found a high prevalence of increased anxiety and panic attacks in the relatives of panic disorder patients (8) and in healthy subjects, suggesting that lactate-induced panic in panic disorder relatives (7) and $\mathrm{CO}_{2}$ challenge test (8) may be a trait marker for genetic vulnerability to anxiety disorders (27). Our data also suggest that the hyperventilation test is a specific marker for some patients but not strong enough to be a trait marker. Cognitive factors are also clearly present in the hyperventilatory test $(25,27)$. The $\mathrm{CO}_{2}$ and lactate infusion tests can be easily compared with a placebo test but the difficulty of using a placebo test in the hyperventilatory test makes its results weaker.

The respiratory challenge test needs more research with a large number of patients to help elucidate the neurobiologic vulnerability of panic disorder patients and may lead to the development of a more specific diagnosis and effective treatments. Our data suggest that there is no association between a family history of panic disorder and hyperreactivity to an acute hyperventilation challenge test. Perhaps cognitive variables should 
be considered to play a specific role in this association since symptoms of a panic attack and acute hyperventilation overlap. The importance of cognitive, genetic and environmental factors in the reactivity to respiratory tests remains unclear. Studies on twins and with cognitive therapy control are needed.

\section{Acknowledgments}

The authors thank Ronir R. Luiz for the statistical analysis.

\section{References}

1. Papp LA, Martinez J M, Klein DF, Coplan J D, Norman RG, Cole R, de J esus MJ , Ross D, Goetz R \& Gorman J M (1997). Respiratory psychophysiology of panic disorder: three respiratory challenges in 98 subjects. American J ournal of Psychiatry, 154: 1557-1565.

2. Gorman JM, Papp LA, Coplan JD, Martinez J M, Lennon S, Goetz RR, Ross $D \&$ Klein DF (1994). Anxiogenic effects of $\mathrm{CO}_{2}$ and hypenventilation in patients with panic disorder. American J ournal of Psychiatry, 151: 547-553.

3. Rapee R, Brown T, Antony M \& Barlow D (1992). Response to hyperventilation and inhalation of $5.5 \%$ carbon dioxide-enriched air across the DSM-III-R anxiety disorders. J ournal of Abnormal Psychology, 101: 538-552.

4. Maddock RJ \& Carter CS (1991). Hyperventilation-induced panic attacks in panic disorder with agoraphobia. Biological Psychiatry, 29: 843-854.

5. Papp LA, Klein DF \& Gorman J M (1998). Carbon dioxide hypersensitivity, hyperventilation, and panic disorder. In: Bellodi L \& Perna G (Editors), The Panic Respiration Connection. Medical Media, Milano.

6. Bandelow $B$, Amering $M$, Benkert $O$, Marks I, Nardi AE, Osterheider M, Tannock C, Tremper J \& Versiani M (1996). Cardio-respiratory and other symptom clusters in panic disorder. Anxiety, 2: 99101.

7. Balon $R$, J ordan $M$, Pohl $R \&$ Yeragani VK (1989). Family history of anxiety disorders in control subjects with lactate-induced panic attacks. American J ournal of Psychiatry, 146: 1304-1306.

8. Perna G, Cocchi S, Bertani A, Arancio C \& Bellodi L (1995). Sensitivity to $35 \% \mathrm{CO}_{2}$ in healthy first-degree relatives of patients with panic disorder. American J ournal of
Psychiatry, 152: 623-625.

9. Holt PE \& Andrews G (1989). Hyperventilation and anxiety in panic disorder, social phobia, GAD and normal controls. Behaviour Research and Therapy, 27: 453-460.

10. Bataglia $M \& \&$ Perna G (1995). The $35 \%$ $\mathrm{CO}_{2}$ challenge in panic disorder: optimization by receiver operating characteristic (roc) analysis. J ournal of Psychiatry Research, 29: 111-119.

11. Papp LA, Klein DF \& Gorman J M (1993). Carbon dioxide hypersensivity, hyperventilation and panic disorder. American J ournal of Psychiatry, 150: 1149-1157.

12. Crowe RR, Noyes R, Pauls DL \& Slymen $D$ (1983). A family study of panic disorder. Archives of General Psychiatry, 40: 10651069.

13. First $M B$, Spitzer $R L$, Gibbon $M \&$ Williams J BM (1997). Structured Clinical Interview Diagnostic (SCID) for DSM -IV Axis I Disorders - Clinician Version (SCID-CV). American Psychiatric Press, Washington.

14. American Psychiatric Association (1994). Diagnostic and Statistical Manual for Mental Disorders. DSM-IV. 4th edn. American Psychiatric Press, Washington.

15. Bech P, Kastrup M \& Rafaelsen OJ (1986). Mini-compendium of rating scales for states of anxiety, depression, mania, schizophrenia with corresponding DSM III syndromes. Acta Psychiatrica Scandinavica, 73 (Suppl 326): 1-37.

16. Sanderson WC, Rapee RM \& Barlow DH (1989). The influence of an illusion of control on panic attacks induced via inhalation of 5.5\% carbon dioxide-enriched air. Archives of General Psychiatry, 46: 157-162.

17. Gorman J M, Askanazi J, Liebowitz MR, Fyer AJ , Stein J , Kinney J M \& Klein DF (1984). Response to hyperventilation in a group of patients with panic disorder. American J ournal of Psychiatry, 141: 857-
861.

18. Ley R (1985). Agoraphobia, the panic attack, and the hyperventilation syndrome. Behaviour Research and Therapy, 23: 7981.

19. Nardi $A E$, Valença $A M$, Nascimento I, Mezzasalma MA \& Zin WA (1999). Panic disorder and hyperventilation. Arquivos de Neuropsiquiatria, 57: 932-936.

20. Garssen B, Buikhuisen M \& Dick R (1996). Hyperventilation and panic attacks. American J ournal of Psychiatry, 153: 513-518.

21. Zandbergen J , Lousberg HA, Pols H, Loof $C \&$ Griez E (1990). Hypercarbia versus hypocarbia in panic disorder. J ournal of Affective Disorders, 18: 75-81.

22. Bass C (1997). Hyperventilation syndrome: a chimera? J ournal of Psychosomatic Research, 42: 421-426.

23. Antony MM, Brown TA \& Barlow DH (1997). Response to hyperventilation and $5.5 \% \mathrm{CO}_{2}$ inhalation of subjects with types of specific phobia, panic disorder, or NO mental disorder. American J ournal of Psychiatry, 154: 1089-1095.

24. Humble M (1987). Aetiology and mechanisms of anxiety disorders. Acta Psychiatrica Scandinavica, 76 (Suppl 335): 15-30.

25. Salkovskis PM, J ones DO \& Clark DM (1986). Respiratory control in treatment of panic attacks: replication and extension with concurrent measurement of behaviour and $\mathrm{PCO}_{2}$. British J ournal of Psychiatry, 148: 526-532.

26. Klein DF (1996). Panic disorder and agoraphobia: hypothesis hothouse. J ournal of Clinical Psychiatry, 57 (Suppl 6): 21-27.

27. Coryell WH (1998). Familial risk for panic disorder and $\mathrm{CO}_{2}$ sensitivity. In: Bellodi $\mathrm{L}$ $\&$ Perna G (Editors), The Panic Respiration Connection. Medical Media, Milano. 